\title{
UCL-Lancet Commission on migration and health
}

Migration is a crucial issue for public health, with currently nearly a quarter of a billion international migrants and more than three times this number of migrants moving within their home country. ${ }^{1,2}$ Migration is not a new phenomenon, but international and internal migration seems to be increasing, triggered by displacement of large numbers of people in low-income and middle-income countries due to conflict, natural disasters, people's search for safety, and voluntary reasons such as economic opportunities. ${ }^{3}$ Although many internal migrants move for economic reasons, forced migration remains an important driver of population mobility with an estimated 40 million people internally displaced due to conflict and violence in $2015 .{ }^{4}$ Migration is shaping world events, with current political and public debates centring around the refugee crises in Europe and heavily heating up the presidential election campaign in the USA. ${ }^{5}$ A well considered and humane policy course offers extraordinary opportunities to make major gains in health and wellbeing for these populations.

The mental and physical health effects of migration on individuals are many and varied. Health might be improved, for example, by moving to a region with a lower disease burden or where safety or financial opportunities are better than their country of origin. Or the effects might be substantially worsened by living and working in poor or substandard conditions or, at its extreme, by being trafficked for forced labour. Women and child migrants are at particular risk of sexual abuse and coercion, including sexual slavery in conflict, early forced marriage, and commercial sex trafficking. Migration can pose heightened risks for vulnerable groups, such as unaccompanied children and people with disabilities. Migrants, especially irregular migrants (people who do not have the required documentation under immigration regulations of the destination country), might experience many barriers to 
accessing health care-such as linguistic, cultural, fear of authorities, or from a poor understanding of the system or entitlements. It is also not unusual for people to be denied access to health care in high-income and middle-income countries on the basis of their immigration status and legal obstacles, such as the Immigration Act 2014 in the UK which introduced health surcharges for migrants. ${ }^{6}$ The UN's Sustainable Development Goals ${ }^{7}$ have universal health coverage as a central element to tackle global health challenges. We might thus question why it is considered legitimate to block access to universal health care for migrants when this would be unthinkable for almost any other group of people?

Migration also affects the host population, the population of origin, and future generations. Although evidence regularly indicates that the economic effects of migration on countries are positive, supporting safe and healthy migration also needs financial investments. The healthcare system might need additional resources or adaptations to manage large population changes. Turkey is home, so far, to 2.7 million Syrian refugees, representing $3.6 \%$ of its population. ${ }^{8}$ For the population where migrants come from, people's mobility might have both positive and negative effects. Loss of healthy and well educated groups, including healthcare workers, can compromise the economy and resources for health, but this movement of people might be counterbalanced by remittances that return to the country. Lastly, migration can have intergenerational effects. Migrants tend to adopt the health profile of their host population, but differences in health can persist for generations through biological, social, cultural, and economic determinants.

To explore the effects of migration on the health of individuals and populations, The Lancet and University College London's Institute for Global Health are launching a joint UCL-Lancet Commission on Migration and Health. The Commission will provide evidence on current issues in migration and health, while concurrently attempting to improve data sources in ways 
that do not stigmatise individuals and to bring particular attention to the wider migrant health challenges, beyond the communities currently advocating for this issue. It will help crystallise understanding of the effects of migration on health in the many groups it affects, by taking a multidisciplinary approach including a historical, sociological, political, epidemiological, and anthropological perspective. The Commission will attract relevant stakeholders and bring together a range of actors, including those from global health and humanitarian medicine communities, to articulate evidence-based approaches to inform public discourse and policy, and identify areas for further research. Particular attention will be given to tackling the key issues that affect the health of migrants both in and between countries, and the necessary policy responses, to ensure the highest attainable standards of health and to synthesise lessons learnt from previous research and the work of the Commission.

The Commission's work will anticipate new policies arising from the changing political context and make evidence-based recommendations to improve such policies. It is our hope that the work of this Commission will provide the foundation for policy makers, advocates, international agencies, health-care systems, and communities to maximise the benefits and reduce the costs of migration on health locally and globally. A meeting of the commissioners, with support from the Wellcome Trust, will be convened in November, 2016, with a call for evidence from the wider migration and health community to be announced in due course.

*Ibrahim Abubakar, Delan Devakumar, Nyovani Madise, Peter Sammonds, Nora Groce, Cathy Zimmerman, Robert W Aldridge, Jocalyn Clark, Richard Horton

University College of London (UCL) Institute for Global Health (IA, DD), UCL Institute of Risk and Disaster Reduction (PS), UCL Leonard Cheshire Disability and Inclusive Development Centre (NG), and UCL Institute for Health Informatics (RWA), UCL, London WC1N 1EH, UK; Centre for Global Health, Population, Poverty and Policy, University of Southampton, 
Southampton, UK (NM); London School of Hygiene and Tropical Medicine, London, UK (CZ); and The Lancet, London, UK (JC, RH)

i.abubakar@ucl.ac.uk

We declare no competing interests.

1 The Lancet. Migrants' health in China. Lancet 2014; 384: 1902.

2 UN Population Division. International migrant stock 2015.

http://www.un.org/en/development/desa/population/migration/data/estimates2/estim ates15.shtml (accessed July 25, 2016).

3 Jakab Z, Severoni S, Ostlin P, Verschuuren M, Stein CE. Refugee and migrant health: a priority in the WHO European Region. Lancet 2015; 386: 2477-78.

4 Internal Displacement Monitoring Centre. IDMC Grid 2016-global report on internal displacement. http://www.internal-displacement.org/globalreport2016/ (accessed July $25,2016)$.

5 The Lancet Infectious Diseases. Migration and health. Lancet Infect Dis 2016; 16: 867.

6 Hargreaves S, Nellums L, Friedland JS, Goldberg J, Murwill P, Jones L. Extending migrant charging into emergency services. BMJ 2016; 352: i685.

7 UN. United Nations sustainable development goals - time for global action for people and planet. Goal 3: Ensure healthy lives and promote well-being for all at all ages. http://www.un.org/sustainabledevelopment/health/ (accessed July 25, 2016).

8 UNHCR Syria Regional Refugee Response. Syria regional refugee response. http://data.unhcr.org/syrianrefugees/country.php?id=224 (accessed July 25, 2016). 